\title{
The relationship between endometrial cytology during estrous cycle and cutoff points for the diagnosis of subclinical endometritis in grazing dairy cows
}

\author{
L. V. Madoz, ${ }^{\star} \dagger$ M. J. Giuliodori,‡ M. Jaureguiberry, ${ }^{*}$ J. Plöntzke,§ M. Drillich,\# and R. L. de la Sota* $\dagger^{1}$ \\ ${ }^{*}$ Cátedra y Servicio de Reproducción Animal, Facultad de Ciencias Veterinarias, Universidad Nacional de La Plata (FCV-UNLP), La Plata, \\ B1900AVW, Argentina \\ †Consejo Nacional de Investigaciones Científicas y Técnicas (CONICET), Buenos Aires, C1033AAJ, Argentina \\ †Cátedra de Fisiología, FCV-UNLP, La Plata, B1900AVW, Argentina \\ §Private practice, 12049 Berlin, Germany; \\ \#Clinic for Ruminants, Section for Herd Health Management, University of Veterinary Medicine Vienna, 1210 Vienna, Austria
}

\section{ABSTRACT}

The objectives of this study were to assess the effect of the stage of estrous cycle on the percentage of endometrial polymorphonuclear cells (PMN) obtained by cytobrush to determine cutoff values for the diagnosis of subclinical endometritis under pastoral conditions, to measure the prevalence of subclinical endometritis 21 to $62 \mathrm{~d}$ in milk (DIM), and to evaluate the effect of subclinical endometritis on reproductive performance in grazing dairy cows. The first experiment was conducted on a commercial dairy farm in Buenos Aires province (Argentina), where 17 postpartum cyclic dairy cows without clinical endometritis were selected and synchronized by Ovsynch protocol. Endometrial cytology (cytobrush technique) and blood (tail vessels) samples were obtained on d $0,4,11$, and 18 of the estrous cycle (corresponding to estrus, metestrus, diestrus, and proestrus, respectively) and used for measuring percentage of PMN and $\mathrm{P}_{4}$ concentration, respectively. The percentage of PMN was determined 3 times by blinded count by 2 operators. Data were analyzed with PROC MIXED, PROC GENMOD, and PROC FREQ from SAS 9.1. The percentage of PMN did not vary with the stage of the estrous cycle. In addition, PMN counts were below any of the reported thresholds in this study (4\%) for most of the cows. Therefore, the risk for false positive test results as a consequence of physiological changes in the counts of PMN during estrous cycle is low. The second experiment was conducted on 4 commercial dairy farms in Buenos Aires province (Argentina), where lactating Holstein dairy cows $(\mathrm{n}=418) 21$ to 62 DIM without clinical endometritis were studied. Samples of endometrial cytology were collected with the cytobrush technique. Data were analyzed with

Received October 15, 2012.

Accepted March 5, 2013.

${ }^{1}$ Corresponding author: dairydoc $82 @$ gmail.com receiver operator characteristic curves with Sigmaplot 10.0, and with PROC GLIMMIX, PROC PHREG, and PROC LIFETEST from SAS 9.1. Cutoff values for the diagnosis of subclinical endometritis in grazing dairy cows are $8 \%$ PMN for 21 to 33 DIM, 6\% PMN for 34 to 47 DIM, 4\% PMN for 48 to 62 DIM, and overall $5 \%$ PMN for 21 to 62 DIM; the prevalence of subclinical endometritis 21 to 62 DIM was $17 \%$. Finally, subclinical endometritis diagnosed at 21 to 62 DIM decreases the hazard for pregnancy (hazard ratio $=0.668 ; 95 \%$ confidence interval $=0.492-0.909)$ and increases the calving to conception interval by d 30 compared with normal cows (median 95\% confidence interval $=133$ vs. 93, respectively).

Key words: dairy cow, subclinical endometritis, cytobrush, estrous cycle

\section{INTRODUCTION}

Endometrial cytology is an accepted practice to evaluate the health status of the uterus (Gilbert et al., 1998) because it is quick, specific, and low cost (Gilbert et al., 2005). Subclinical endometritis is defined based on the proportion of polymorphonuclear cells (PMN) in endometrial samples (Sheldon et al., 2006). Cytobrush has been described as the best technique for obtaining uterine cytology in cows due to its reliability and lack of cell distortion (Kasimanickam et al., 2005). Flushing the uterus with low volumes of fluids to collect endometrial cells, however, is also a generally accepted technique (Gilbert et al., 2005; Sheldon et al., 2006). It is well known that cows experience many physiological and structural changes during the estrous cycle depending on the prevailing hormonal profile (Ohtani et al., 1993). One of these changes is an increased infiltration of PMN into the endometrium, especially from proestrus through metestrus (Ohtani et al., 1993). To the best of our knowledge, it is unknown if this physiological change in the percentage of PMN may cause false positive diagnoses of endometritis. 
Conversely, an early and accurate diagnosis of subclinical endometritis would allow us to identify cows for treatment (and cure) and recognize cows with compromised fertility (i.e., mild inflammation) and avoid inseminating them. The main problem regarding the diagnosis of subclinical endometritis is that no general consensus exists among researchers about the cutoff values to differentiate diseased from healthy cows. Some researchers have used receiver operator characteristic (ROC) analysis to establish cutoff values (Kasimanickam et al., 2004; Galvão et al., 2009), whereas others used quartiles (McDougall et al., 2011) or arbitrary values (Gilbert et al., 2005; Hammon et al., 2006; Plöntzke et al., 2010). In addition, differences in the timing of sampling and in the diagnostic test used for endometritis have been observed, making comparisons among studies almost unfeasible. The reported prevalence of subclinical endometritis ranges from $12 \%$ (Barlund et al., 2008) to more than 50\% (Gilbert et al., 2005; Hammon et al., 2006; Galvão et al., 2009). Regarding the effect of subclinical endometritis on reproductive performance, some researchers described a negative effect; specifically, 2 studies (using ROC curve to determine cutoff values) reported an increase of 30 to $60 \mathrm{~d}$ in the calving to conception interval in cows with subclinical endometritis (Kasimanickam et al., 2004; Galvão et al., 2009). Another study, carried out in repeat breeding dairy cows (also using cutoff values obtained by ROC curve), found a reduction in the conception rate at the next AI from 47 to $5 \%$ in cows with subclinical endometritis (Salasel et al., 2010). Conversely, other studies did not find any negative effect (Kasimanickam et al., 2006; Plöntzke et al., 2010).

Finally, most of the cited studies were carried out in dairy cows reared under confinement systems mainly in Europe and North America. Therefore, a lack of information exists about the effect of the estrous cycle on the likelihood for false positive diagnosis of subclinical endometritis, the cutoff values for its diagnosis, and also on its effect on reproductive performance in grazing dairy cows.

\section{Objectives}

The objectives of this study were (1) to assess the effect of the physiological changes in the influx of PMN to the uterus through the estrous cycle on the diagnostic output of subclinical endometritis performed by cytobrush, (2) to determine the cutoff values for the diagnosis of subclinical endometritis under pastoral conditions, (3) to determine the prevalence of subclinical endometritis from 21 to 62 DIM, and (4) to evaluate the effect of subclinical endometritis on reproductive performance in grazing dairy cows. The hypotheses to test were (1) that the greater infiltration of leucocytes (i.e., PMN) to the uterus, observed from proestrus through metestrus, would not induce an increase of false positive diagnoses; (2) that the prevalence of subclinical endometritis is lower under grazing situations from what is reported for more intensively and metabolically stressful production systems; and (3) that subclinical endometritis reduces reproductive performance in grazing dairy cows.

\section{MATERIALS AND METHODS}

\section{Experiment 1}

Animals and Sampling. This study was performed on a commercial dairy farm located in Buenos Aires province $\left(34^{\circ} 56^{\prime} \mathrm{S}, 58^{\circ} 47^{\prime} \mathrm{W}\right.$, Argentina) where lactating Holstein cows $(\mathrm{n}=53) 27$ to 56 DIM were enrolled. Cows with a BCS $<2.5$, retention of fetal membranes, or abortion were excluded from the analysis. All cows were examined by gloved-hand vaginal inspection and their vaginal discharge (VD) was classified as VD-0 (normal clear discharge), VD-1 (clear discharge with flecks of pus), VD-2 (muco-purulent not fetid discharge), and VD-3 (purulent or brown-colored, and fetid; Sheldon et al., 2002; Williams et al., 2005). Cows also had their ovaries scanned by ultrasound (7.5 MHz; Mindray 6600Vet, Nanshan, China) and categorized as cyclic (with corpora lutea or follicles $>8 \mathrm{~mm}$ in diameter) or acyclic (no corpora lutea and no follicles $>8$ $\mathrm{mm}$ in diameter). Only cyclic cows with normal VD (without pus) were selected $(\mathrm{n}=30)$ and had estrus synchronized with an Ovsynch protocol (d $-9=8$ $\mu \mathrm{g}$ of Buserelin, GnRH; d $-2=150 \mu \mathrm{g}$ of Enzaprost, D-cloprostenol, and d $0=8 \mu \mathrm{g}$ of Buserelin, GnRH; Biogenesis Bagó, Argentina). Cows that were absent for any of the sampling days or ultrasound scanning (n $=4)$, failed to complete the Ovsynch protocol $(\mathrm{n}=5)$, did not respond to the Ovsynch $(\mathrm{n}=3)$, or those having clinical mastitis $(n=1)$ were excluded. Therefore, only cows that completed the protocol $(\mathrm{n}=17)$ were sampled from tail vessels for $\mathrm{P}_{4}$ measurement and from endometrium for cytological evaluation on d $0,4,11$, and 18 (representing estrus, metestrus, diestrus, and proestrus, respectively).

Progesterone Measurement. Serum was harvested within $2 \mathrm{~h}$ postsampling and stored at $-20^{\circ} \mathrm{C}$ until analyzed by RIA with a commercial kit (Coat-ACount, Progesterone; Diagnostic Product Corporation, Los Angeles, CA). Intra-assay coefficients of variation were $5.14 \%$ for the high pool $(6.45 \mathrm{ng} / \mathrm{mL})$ and $10.21 \%$ for the low pool $(0.8 \mathrm{ng} / \mathrm{mL})$.

Cytological Evaluation. Samples of endometrial cytology were collected using a cytobrush modified for 
use in cattle. A stainless steel gun was attached with a sterile brush (Medibrush XL, Medical Engineering Co. SA, Buenos Aires, Argentina), commonly used in human gynecology. The gun was covered for protection from vaginal contamination with a bovine split universal sheath (IMV Technologies, Paris France). Once the cervix was passed, the cytobrush was exposed and rolled onto the endometrium and then reintroduced back in the protective sheath of the gun. Outside the cow, the cytobrush was removed from the gun grip and rotated onto a microscopic slide. The smear was air-dried, fixed with ethyl alcohol (Roby, Argencos SA, San Martín, Argentina) to preserve cellular morphology, and stained (Tinción 15, Biopur, Rosario, Argentina). Evaluations were performed under a microscope at $400 \times$ magnification (Nikon Eclipse E200, Tokyo, Japan) where 200 cells were counted to determine the percentages of PMN and leukocyte mononuclear cells. The slides were blinded and assessed twice by the same investigating clinician and once more by another operator. All samples were photographed (4 per sample) and endometrial cells (10 per sample) were measured with an image processing software (Image J; National Institutes of Health, Bethesda, MD) to determine the area $\left(\mu^{2}\right)$, the perimeter $(\mu)$, and the Feret diameter $(\mu)$.

Statistical Analysis. Data are shown as LSM \pm $\mathrm{SE}$ or as a percentage. Statistical significance was set at $P<0.05$, and a trend for significance was set at $P$ $<0.10$. The cow was considered the experimental unit. Progesterone concentration, area, perimeter, and Feret diameter of endometrial cells were analyzed with PROC MIXED (SAS, 2003) as repeated measures. The model included the random effect of the cow and the fixed effect of time (sampling day $=0$ vs. 4 vs. 11 vs. 18). The covariance structure having the smallest Akaike's information criterion and Schwarz's Bayesian criterion was used (Littell et al., 2002). A polynomial contrast was used to test the linear, quadratic, and cubic effects of time on response variables. The logistic model for the percentage of PMN and mononuclear leukocytes included the fixed effects of time (sampling day $=0$ vs. 4 vs. 11 vs. 18). When time had an effect, an extra model was run including time as a continuous variable (sampling days). The models were analyzed with PROC GENMOD of SAS 9.1 (SAS, 2003) with Binomial distributions and Logit link functions. Finally, agreement between the 2 readings of the same clinician and between the 2 operators were evaluated by the Kappa coefficient with the PROC FREQ of SAS (SAS, 2003).

\section{Experiment 2}

Animals and Sampling. This study was performed on 4 commercial grazing dairy farms located in Carlos
Casares $\left(35^{\circ} 37.4^{\prime} \mathrm{S}, 61^{\circ} 21.6^{\prime} \mathrm{W}\right)$, Brandsen $\left(35^{\circ} 10.4^{\prime} \mathrm{S}\right.$, $\left.58^{\circ} 14.0^{\prime} \mathrm{W}\right)$, América $\left(35^{\circ} 28.9^{\prime} \mathrm{S}, 62^{\circ} 58^{\prime} \mathrm{W}\right)$, and Carmen de Areco $\left(34^{\circ} 50.8^{\prime} \mathrm{S}, 58^{\circ} 27^{\prime} \mathrm{W}\right)$, Argentina, where lactating Holstein dairy cows $(\mathrm{n}=418)$ were enrolled. Cows with dystocia, retained fetal membranes, or abortion were excluded. Between 21 to 62 DIM, all cows were examined for clinical endometritis through VD evaluation as described previously. Only cows without clinical endometritis having VD-0 (normal, clear, with no flakes of pus) were included in the study. Samples of endometrial cytology were collected using a cytobrush and percentage of PMN was estimated as previously described.

At the end of the voluntary waiting period, cows were observed for signs of estrus twice a day and cows in heat were AI with the a.m.-p.m. rule. Pregnancy diagnosis was performed by palpation per rectum by a veterinarian at $45 \pm 3 \mathrm{~d}$ after AI.

Statistical Analysis. Data are shown as LSM \pm SE or as a percentage. Statistical significance was set at $P<0.05$ and a trend for significance was set at $P$ $<0.10$. The cow was considered the experimental unit. Receiver operator characteristic analyses were used to determine critical cutoffs for predicting subclinical endometritis by using Sigma plot 10.0 (Systat, 2006) for the intervals 21 to 33,34 to 47,48 to 62 , and the overall interval of 21 to 62 DIM. Cows were dichotomized into those below or above the median days open $(100 \mathrm{~d})$. Sensitivity was the proportion of cows having longer than the median days open that were above a given threshold, and specificity was the proportion of animals having shorter than the median days open that were below a given threshold (Greiner et al., 2000). The critical threshold was the point on the ROC curve that had the highest combined sensitivity and specificity. The logistic models for pregnancy rates at first AI, by 100 DIM, and by 200 DIM included the random effect of dairy farm $(\mathrm{n}=4)$ and the fixed effects of parity ( 1 vs. $\geq 2$ ), season (spring vs. summer vs. autumn vs. winter), subclinical endometritis (yes vs. no), and their second-order interactions. The models were analyzed with PROC GLIMMIX of SAS 9.1 (SAS, 2003) with Binomial distributions and Logit link functions. Modeling was performed using a manual backward elimination method with an exclusion criteria set at $P$ $>0.15$. Cox's proportional hazards regression models were analyzed with PROC PHREG (SAS, 2003) and included the fixed effects of parity ( 1 vs. $\geq 2$ ), season (spring vs. summer vs. autumn vs. winter), subclinical endometritis (yes vs. no), and their second-order interactions. Another Cox's model was run including the percentage of PMN as a continuous predictor. Modeling was performed using a manual backward elimination method with an exclusion criteria set at $P>0.15$. 
Time intervals (median $\pm 95 \% \mathrm{CI}$ ) for days open and survival function estimates were obtained from PROC LIFETEST (SAS, 2003).

\section{RESULTS}

\section{Experiment 1}

Time had an effect on $\mathrm{P}_{4}$ concentration $(P<0.001$; Table 1), and according to the contrast it was cubic $(P=0.010)$. Conversely, time had no effect on area $(P$ $=0.125)$, perimeter $(P=0.370)$, and Feret diameter $(P=0.480)$ of endometrial cells (Table 1$)$. Time (as continuous predictor) had no effect on the percentage of PMN ( $P=0.827$; Figure 1 and Table 1$)$. In addition, PMN counts were far below the threshold of $4 \%$ for most of the cows. Conversely, time had an effect on the percentage of leukocyte mononuclear cells [odds ratio $(\mathbf{O R})=0.953,95 \% \mathrm{CI}=0.921-0.987, P=0.015$; Table 1]. Thus, cells decreased by $4.7 \%$ per day during the estrous cycle $[(\mathrm{OR}-1) \times 100$ was used to transform OR into percentage; Allison, 1999]. Finally, the agreements were high not only for the same operator readings ( $\kappa$ $=0.81$ ) but also for the readings of the 2 operators ( $\kappa$ $=0.76)$.

\section{Experiment 2}

The critical thresholds for predicting subclinical endometritis at 21 to 33 DIM was $8 \%$ PMN (ROC area $=0.65 \pm 0.06, P=0.023, \mathrm{Se}=0.37$, and $\mathrm{Sp}=0.89)$; the cutoff for 34 to 47 DIM was $6 \%$ PMN (ROC area $=0.59 \pm 0.05, P=0.056, \mathrm{Se}=0.23$, and $\mathrm{Sp}=0.93)$; the cutoff for 48 to 62 DIM was $4 \%$ PMN (ROC area $=$ $0.63 \pm 0.06, P=0.038, \mathrm{Se}=0.22$, and $\mathrm{Sp}=0.82)$; and the cutoff for the overall period (21 to 62 DIM) was $5 \%$ PMN (ROC area $=0.61 \pm 0.03, P<0.001, \mathrm{Se}=0.25$, and $\mathrm{Sp}=0.89$; Figure 1).

Prevalence of Subclinical Endometritis. We found a prevalence of $21.5 \%$ from 21 to 33 DIM, of $16 \%$

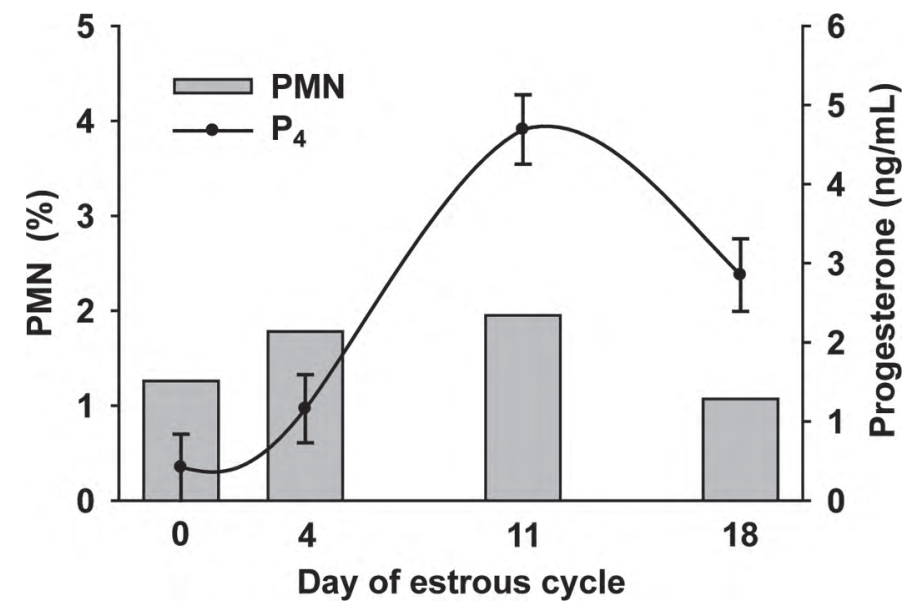

Figure 1. Effect of day of estrous cycle on the percentage of polymorphonuclear neutrophils (PMN) in samples of endometrial cytology taken with a cytobrush in grazing Holstein dairy cows $(\mathrm{n}=17)$. Time had no effect on PMN $(P=0.827)$ but affected progesterone concentration $(P<0.001)$.

from 34 to 47 DIM, of $16 \%$ from 48 to 61 DIM, and an overall prevalence of $17 \%$ for the full period from 21 to 62 DIM.

Pregnancy Rate at First AI. Subclinical endometritis numerically reduced the odds for pregnancy at first insemination [adjusted OR $(\mathbf{A O R})=0.600$, $95 \% \mathrm{CI}=0.318-1.132, P=0.115$; Table 2]; however, this was not statistically significant. Parity and season had no effect ( $P=0.600$ and 0.280 , respectively).

Pregnancy Rate by 100 DIM. Subclinical endometritis showed a strong tendency to reduce the odds for pregnancy by $100 \mathrm{DIM}(\mathrm{AOR}=0.556,95 \% \mathrm{CI}=$ $0.307-1.008, P=0.053$; Table 2 ). Cows of parity $\geq 2$ had lower odds for pregnancy than those of parity 1 $(\mathrm{AOR}=0.559,95 \% \mathrm{CI}=0.333-0.939, P=0.029)$. Finally, season had no effect on the risk $(P=0.723)$.

Pregnancy Rate by 200 DIM. Subclinical endometritis reduced the odds for pregnancy by 200 DIM, however, this effect was statistically not significant

Table 1. Progesterone concentration, characteristics of endometrial cells, and counts of leukocyte cells during estrous cycle of grazing Holstein dairy cows $(\mathrm{n}=17)$

Day of estrous cycle

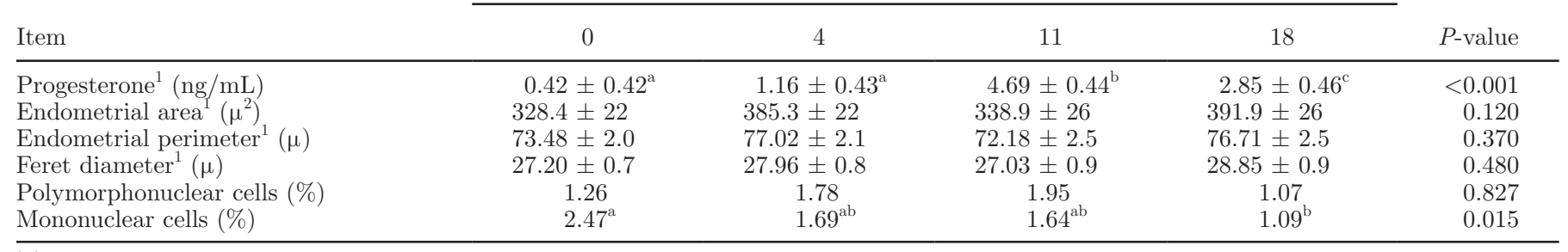

\footnotetext{
${ }^{\mathrm{a}-\mathrm{c}}$ Different letters within a row means $P<0.05$.
}

${ }^{1}$ Values expressed as LSM $\pm \mathrm{SE}$. 
Table 2. Effect of subclinical endometritis on the risk for and the hazard of pregnancy in grazing Holstein dairy cows $(\mathrm{n}=418)$

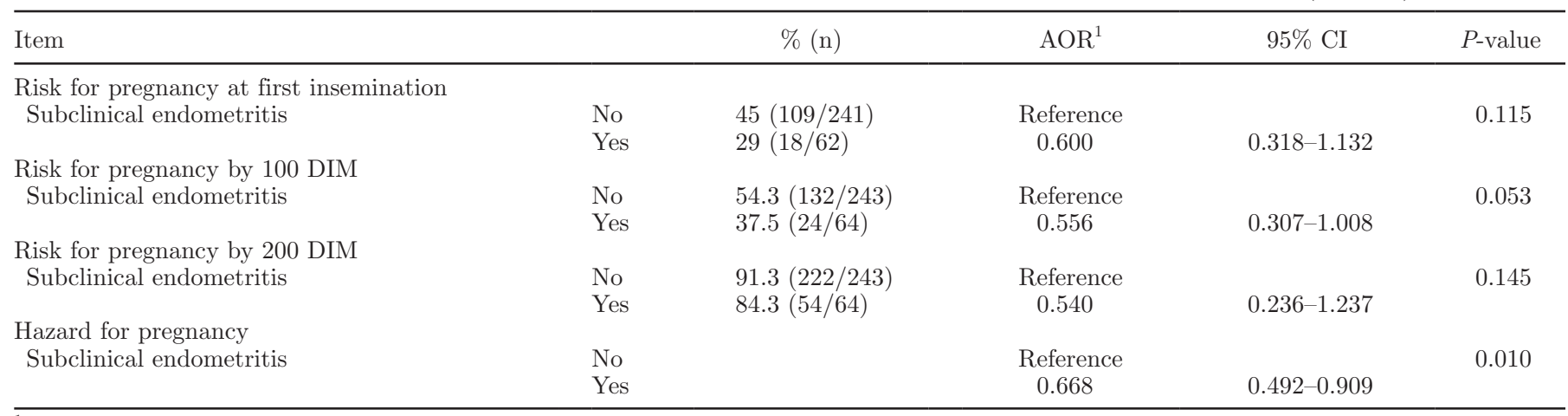

${ }^{1} \mathrm{AOR}=$ adjusted odds ratio.

$(\mathrm{AOR}=0.540,95 \% \mathrm{CI}=0.236-1.237, P=0.145$; Table 2). Cows of parity $\geq 2$ had lower odds for pregnancy than those of parity $1(\mathrm{AOR}=0.351,95 \% \mathrm{CI}=$ $0.128-0.963, P=0.042)$. Finally, season had no effect on the risk $(P=0.482)$.

Calving to Conception Interval. Subclinical endometritis reduced the hazard for pregnancy (hazard ratio $=0.668,95 \% \mathrm{CI}=0.492-0.909, P=0.010$; Table $2)$. Parity $\geq 2$ had lower hazard for pregnancy than parity 1 cows (hazard ratio $=0.910,95 \% \mathrm{CI}=0.827-1.001$, $P=0.048)$. Subclinical endometritis by parity had no effect $(P=0.22)$. Conversely, the percentage of PMN had an effect on the hazard for pregnancy (hazard ratio $=0.987,95 \% \mathrm{CI}=0.974-1.001, P=0.062)$. So, the hazard for pregnancy decreased $1.3 \%$ per every increase in percentage of PMN [(hazard ratio -1$) \times 100$ was used to transform hazard ratio into percentage; Allison, 1999]. Finally, cows having subclinical endometritis had a longer calving to conception interval (median, 95\% CI $=133.0,109.0-166.0$ ) than normal cows (median, $95 \%$ $\mathrm{CI}=93.0,86.0-166.0$, log-rank test $=10.53, \mathrm{df}=1, P$ $=0.001 ;$ Figure 2).

\section{DISCUSSION}

One of the objectives of this study was to assess if the increase in PMN during proestrus and metestrus (Kojima and Selander, 1970; Ohtani et al., 1993; Priedkalns, 1993; Dhaliwal et al., 2001) could affect the diagnosis of subclinical endometritis. We found that the counts of PMN did not change during the estrous cycle and were always below any of the reported threshold values for the diagnosis of subclinical endometritis. Therefore, our results confirm our hypothesis stating that the percentage of PMN does not vary significantly along the estrous cycle in cyclic normal cows so as to produce a false positive diagnosis of subclinical endometritis by using the cytobrush technique. To the best of our knowledge, this is the first study documenting that concept. One possible explanation for our finding could be that the infiltration of PMN is located mainly below the surface of the endometrium (Ohtani et al., 1993), whereas the cytobrush samples are obtained from the most superficial layers.

Regarding the diagnosis of subclinical endometritis under pastoral conditions, we obtained cutoff values of 8, 6 , and $4 \%$ PMN for 21 to 33,34 to 47 , and 48 to 62 DIM, respectively, using ROC analysis. These values are very similar to $8.5,6.5$, and $4.0 \%$ as recently reported in the United States (Galvão et al., 2009), but much lower than the $18 \%$ found in Canada (Kasimanickam et al., 2004); both studies also determined values by using ROC analysis. Other researchers have used quartiles to determine the threshold (McDougall et al., 2011) or even arbitrary cutoff points of $5 \%$ (Gilbert et al.,

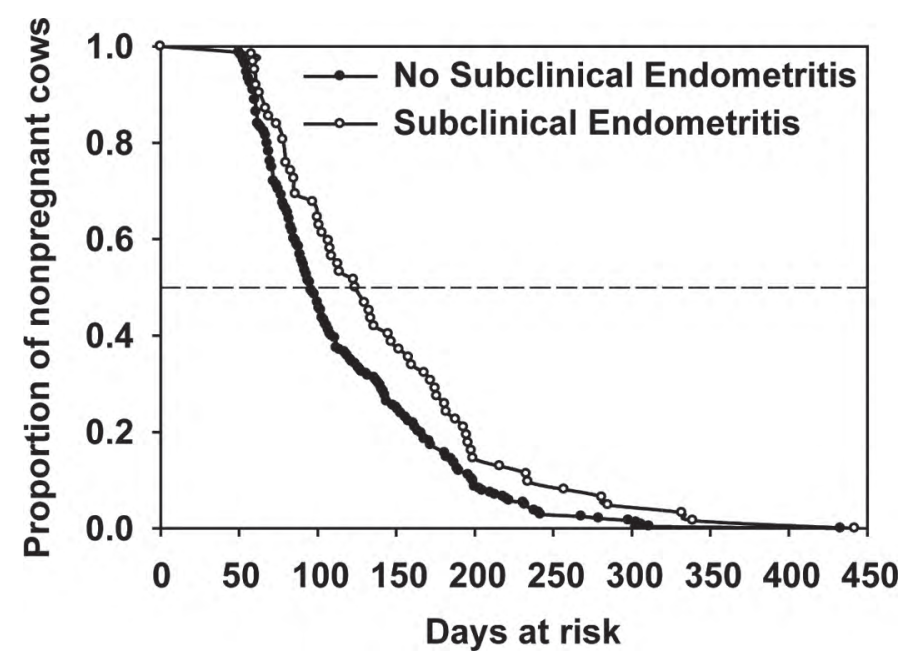

Figure 2. Effect of subclinical endometritis on the calving to conception interval in grazing Holstein dairy cows $(n=418)$. Subclinical endometritis was defined as cows having $>5 \%$ of polymorphonuclear cells on cytobrush-obtained uterine samples 21 to 62 DIM. Median (95\% CI) calving to conception intervals were 133 (109-166) for cows having subclinical endometritis and 93 (86-166) for normal cows (logrank test $=10.53$, df $=1, P=0.001)$. 
2005; Plöntzke et al., 2010) and 25\% (Hammon et al., 2006) to differentiate positive and negative test results. Hence, our results are very similar to those reported by Galvão et al. (2009), and therefore it could be established that the lower percentage of PMN associated with reduced reproductive performance is around $4 \%$.

Another objective of this study was to test the hypothesis that the prevalence of subclinical endometritis is lower under grazing systems than under confinement dairy systems. We found a prevalence of $17 \%$ at 21 to 62 DIM, whereas the reported prevalence in Europe and North America are 41 and 16\% (for 21-27 and 35-41 DIM, respectively; Raab et al., 2004), 35 and $34 \%$ (for 20-33 and 34-47 DIM, respectively; Kasimanickam et al., 2005), 53\% (for 40-60 DIM; Gilbert et al., 2005), 67,38 , and $37 \%$ (for 21,35 , and 49 DIM, respectively; Galvão et al., 2009), and 52\% (for 25-31 DIM; Hammon et al., 2006). The results from our study may underestimate the prevalence of subclinical endometritis because only cows that did not have abnormal uterine discharge and did not have dystocia, retained fetal membranes, and abortions were included. In a previous study by Kasimanickam et al. (2004), only cows with no abnormal uterine discharge were included in the study. Furthermore, in that study cows were excluded if they received systemic antibiotic therapy within 7 d before enrollment, intrauterine therapy or reproductive hormone administration in the current lactation before enrollment, or had abnormal internal genitalia including adhesions or pyometra. Following this rationale, in our study very few cows were left that had dystocia, retained fetal membranes, and abortions and did not receive systemic antibiotic therapy, intrauterine therapy, or reproductive hormones; hence, those cows were excluded from the study to simplify the statistical analysis. Therefore, even if our study slightly underestimates the prevalence of subclinical endometritis, it still supports our hypothesis that the prevalence of subclinical endometritis is lower in grazing system than in confinement systems. One possible explanation could be that cows under grazing conditions are less metabolically stressed due to their lower milk yield compared with cows reared in high-producing intensive systems. Thus, our less-stressed cows could decrease the uterine bacterial load more efficiently than more-stressed cows do.

Regarding our final hypothesis, that subclinical endometritis reduces reproductive performance in grazing dairy cows, we found that cows with subclinical endometritis have a $16 \%$ lower pregnancy rate and take $30 \mathrm{~d}$ longer to get pregnant. Our data supports the results from previous studies reporting detrimental effects of subclinical endometritis on reproduction (Kasimanickam et al., 2004; Galvão et al., 2009). One reason for its deleterious effects on reproduction could be through the clear disruption of the uterine environment (Bondurant, 1999; Sheldon and Dobson, 2004), for example, through an alteration in the endometrial synthesis of prostaglandins (Gabler et al., 2009) or epidermal growth factor (Katagiri and Takahashi, 2004).

\section{CONCLUSIONS}

In conclusion, the physiological infiltration of PMN to the endometrium did not change the percentage of PMN in cytobrush samples along the stages of estrous cycle enough to affect the diagnosis of subclinical endometritis in clinically healthy cows. Cutoff values for the diagnosis of subclinical endometritis in clinically healthy grazing dairy cows are $8 \%$ for 21 to 33 DIM, $6 \%$ for 34 to 47 DIM, $4 \%$ for 48 to 62 DIM, and a global cutoff is $5 \%$ PMN for 21 to 62 DIM. The prevalence of subclinical endometritis postpartum in lactating dairy cows on a grazing system in Argentina was $17 \%$. Finally, subclinical endometritis decreases conception rate to first service and increases the calving to conception interval by $30 \mathrm{~d}$.

\section{ACKNOWLEDGMENTS}

This study was financed by a Grant to R. L. de la Sota (V11/134, Proyecto de Incentivos, Universidad Nacional de La Plata, La Plata, Argentina). The authors thank the private practice veterinarians, farm owners, and farm and personnel for their help and support during the study.

\section{REFERENCES}

Allison, P. 1999. Logistic regression using SAS: Theory and Applications. SAS Institute Inc., Cary, NC.

Barlund, C. S., T. D. Carruthers, C. L. Waldner, and C. W. Palmer. 2008. A comparison of diagnostic techniques for postpartum endometritis in dairy cattle. Theriogenology 69:714-723.

Bondurant, R. H. 1999. Inflammation in the bovine female reproductive tract. J. Anim. Sci. 77(Suppl. 2):101-110.

Dhaliwal, G. S., R. D. Murray, and Z. Woldehiwet. 2001. Some aspects of immunology of the bovine uterus related to treatments for endometritis. Anim. Reprod. Sci. 67:135-152.

Gabler, C., M. Drillich, C. Fischer, C. Holder, W. Heuwieser, and R. Einspanier. 2009. Endometrial expression of selected transcripts involved in prostaglandin synthesis in cows with endometritis. Theriogenology 71:993-1004.

Galvão, K. N., M. Frajblat, S. Brittin, W. Butler, C. Guard, and R. Gilbert. 2009. Effect of prostaglandin $F_{2 \alpha}$ on subclinical endometritis and fertility in dairy cows. J. Dairy Sci. 92:4906-4913.

Gilbert, R. O., S. T. Shin, C. L. Guard, and H. Erb. 1998. Incidence of endometritis and effects on reproductive performance of dairy cows. Theriogenology 49:251.

Gilbert, R. O., S. T. Shin, C. L. Guard, H. N. Erb, and M. Frajblat. 2005. Prevalence of endometritis and its effects on reproductive performance of dairy cows. Theriogenology 64:1879-1888.

Greiner, M., D. Pfeiffer, and R. D. Smith. 2000. Principles and practical application of the receiver-operating characteristic analysis for diagnostic tests. Prev. Vet. Med. 45:23-41. 
Hammon, D. S., I. M. Evjen, T. R. Dhiman, J. P. Goff, and J. L. Walters. 2006. Neutrophil function and energy status in Holstein cows with uterine health disorders. Vet. Immunol. Immunopathol. 113:21-29.

Kasimanickam, R., J. M. Cornwell, and R. L. Nebel. 2006. Effect of presence of clinical and subclinical endometritis at the initiation of Presynch-Ovsynch program on the first service pregnancy in dairy cows. Anim. Reprod. Sci. 95:214-223.

Kasimanickam, R., T. F. Duffield, R. A. Foster, C. J. Gartley, K. E. Leslie, J. S. Walton, and W. H. Johnson. 2004. Endometrial cytology and ultrasonography for the detection of subclinical endometritis in postpartum dairy cows. Theriogenology 62:9-23.

Kasimanickam, R., T. F. Duffield, R. A. Foster, C. J. Gartley, K. E. Leslie, J. S. Walton, and W. H. Johnson. 2005. A comparison of the cytobrush and uterine lavage techniques to evaluate endometrial cytology in clinically normal postpartum dairy cows. Can. Vet. J. $46: 255-259$.

Katagiri, S., and Y. Takahashi. 2004. Changes in EGF concentrations during estrous cycle in bovine endometrium and their alterations in repeat breeder cows. Theriogenology 62:103-112.

Kojima, Y., and U. Selander. 1970. Cyclical changes in the fine structure of bovine endometrial gland cells. Z. Zellforsch. Mikrosk. Anat. 104:69-86.

Littell, R. C., W. W. Stroup, and R. J. Freund. 2002. SAS for Linear Models. SAS Institute Inc., Cary, NC.

McDougall, S., H. Hussein, D. Aberdein, K. Buckle, J. Roche, C. Burke, M. Mitchell, and S. Meier. 2011. Relationships between cytology, bacteriology and vaginal discharge scores and reproductive performance in dairy cattle. Theriogenology 76:229-240.

Ohtani, S., K. Okuda, K. Nishimura, and S. Mohri. 1993. Histological changes in bovine endometrium during the estrous cycle. Theriogenology 39:1033-1042.
Plöntzke, J., L. V. Madoz, R. L. De la Sota, M. Drillich, and W. Heuwieser. 2010. Subclinical endometritis and its impact on reproductive performance in grazing dairy cattle in Argentina. Anim. Reprod. Sci. 122:52-57.

Priedkalns, J. 1993. Sistema Reproductor Femenino. Pages 282-283 in Histología Veterinaria. D. Dellmann, ed. Acribia, Zaragoza, Spain.

Raab, D., M. Drillich, and W. Heuwiesser. 2004. Diagnosis of subclinical endometritis and its effects on reproductive performance. Page 166 in the 36th Ann. Conf. Am. Assoc. Bovine Pract. (AABP), Columbus, OH. AABP Press, Auburn, AL.

Salasel, B., A. Mokhtari, and T. Taktaz. 2010. Prevalence, risk factors for and impact of subclinical endometritis in repeat breeder dairy cows. Theriogenology 74:1271-1278.

SAS. 2003. SAS and STAT User's Guide, Release 9.1. SAS Institute Inc., Cary, NC.

Sheldon, I. M., and H. Dobson. 2004. Postpartum uterine health in cattle. Anim. Reprod. Sci. 82-83:295-306.

Sheldon, I. M., G. S. Lewis, S. LeBlanc, and R. O. Gilbert. 2006. Defining postpartum uterine disease in cattle. Theriogenology 65:1516-1530

Sheldon, I. M., D. E. Noakes, A. N. Rycroft, and H. Dobson. 2002. Effect of postpartum manual examination of the vagina on uterine bacterial contamination in cows. Vet. Rec. 151:531-534.

Systat. 2006. Sigmaplot User's Guide, version 10.0. Systat Software Inc., Chicago, IL.

Williams, E. J., D. P. Fischer, D. U. Pfeiffer, G. C. England, D. E. Noakes, H. Dobson, and I. M. Sheldon. 2005. Clinical evaluation of postpartum vaginal mucus reflects uterine bacterial infection and the immune response in cattle. Theriogenology 63:102-117. 